\title{
SITUS INVERSUS TOTALIS WITH DEXTROCARDIA IN FOUR INDIANS
}

\author{
Samrendra Nath Pathak1, Satya Prakash Shankaram², Jagriti Narayan ${ }^{3}$
}

${ }^{1}$ Assistant Professor, Department of Radiology, Patna Medical College Hospital, Patna.

2Junior Resident, Department of Radiology, Patna Medical College Hospital, Patna.

3Junior Resident, Department of Radiology, MGM Medical College, Kishanganj, Bihar.

\section{ABSTRACT}

Situs inversus with dextrocardia is a congenital condition, in which there is inverted positioning of abdominal viscera with a right-sided heart. This inversion is the mirror image of the normal anatomy usually seen in routine medical test and examination. It may be isolated or associated with various malformation. Eg. Cardiac defects, Kartagener syndrome or spleen anomaly.

\section{KEYWORDS}

Situs Inversus, Dextrocardia, Ciliary Dyskinesia, Malrotation.

HOW TO CITE THIS ARTICLE: Pathak SN, Shankaram SP, Narayan J. Situs inversus totalis with dextrocardia in four Indians. J. Evolution Med. Dent. Sci. 2016;5(80):6014-6017, DOI: 10.14260/jemds/2016/1358

\section{INTRODUCTION}

Situs inversus (Also called situs transversus) is a congenital condition, in which the major abdominal visceral organs are reversed or mirrored from their normal position.

Dextrocardia is the congenital condition, in which the heart is positioned on right side instead of left side of the thoracic cavity.

Most people are usually unaware of their unusual anatomy until they seek medical attention for some unrelated medical reason.

\section{CASE REPORT}

We report four cases who were sent to our department from the general outpatient department for routine chest X-ray (PA) and transabdominal ultrasound. One case was sent for CECT abdomen for some other medical condition.

\section{CASE 1}

A 14 yr. Indian male had right-sided flank pain for one week. He had no history of cough, haematuria. He was neither hypertensive nor diabetic. BP was 118/76, resp rate was $74 / \mathrm{min}$.

On auscultation, heart sounds were located on right fifth intercostal space. Routine blood profile including blood sugar and serum creatinine were within normal limits.

On transabdominal ultrasound scan, stomach and spleen were noted on right side while liver, gall bladder were on left side. A calculus of size $8 \mathrm{~mm}$ was seen in midpole of right kidney. Malrotation was suspected for which barium study was done.

Barium study revealed gastric fundus on the right. Echocardiography was normal.

Financial or Other, Competing Interest: None.

Submission 07-06-2016, Peer Review 22-09-2016,

Acceptance 28-09-2016, Published 06-10-2016.

Corresponding Author:

Dr. Samrendra Nath Pathak,

301-C, Nandan Tower Colony More,

Kankarbagh, Patna.

E-mail: snpathak301@gmail.com

DOI: $10.14260 /$ jemds/2016/1358

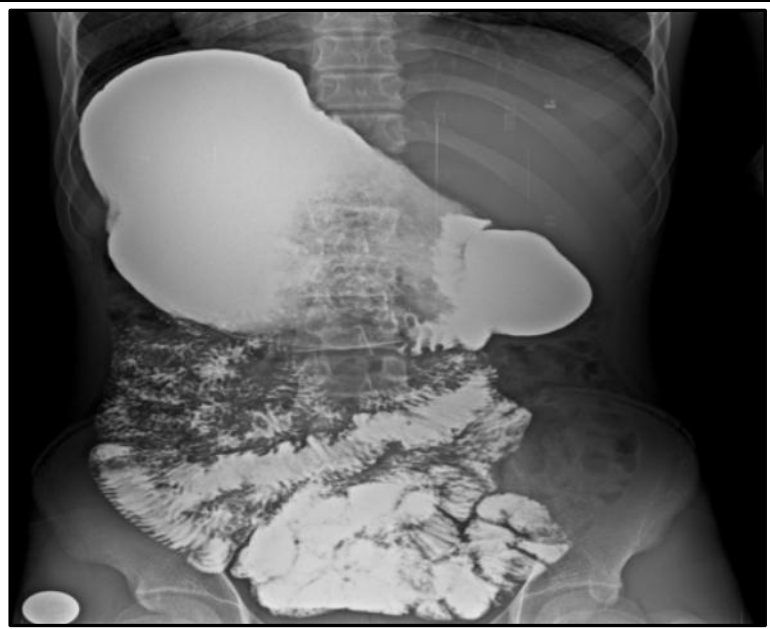

Fig. 1: Gastric Fundus on the Right with Abnormal Positioning of Duodenojejunal Junction in Barium Study

X-ray chest (PA) view shows cardiac apex in the right hemithorax with right-sided fundal gas shadow.

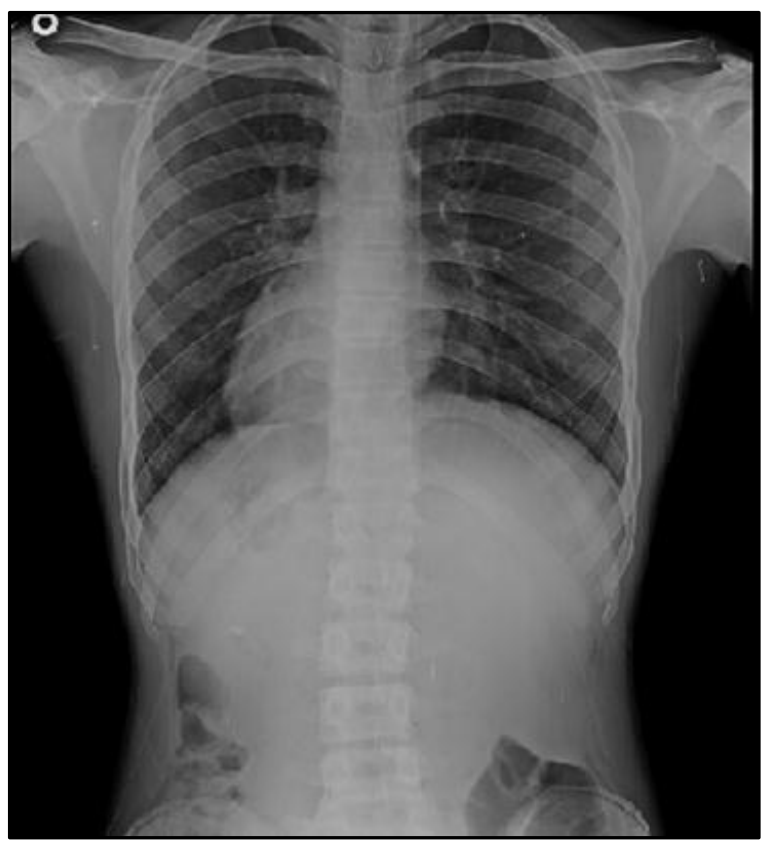

Fig. 2: X-Ray Chest (PA) View showing Cardiac Apex in the Right Hemithorax with Right-Sided Fundal Gas Shadow 
Computed Tomography (CT) chest and abdomen revealed transposition of abdominal viscera with liver and gall bladder on left side and stomach and spleen on right side. Heart was seen on right side with ascending aorta on left and descending aorta on right side. A radiodense calculus of size $8 \mathrm{~mm}$ seen on midpole of right kidney with no evidence of hydronephrosis.

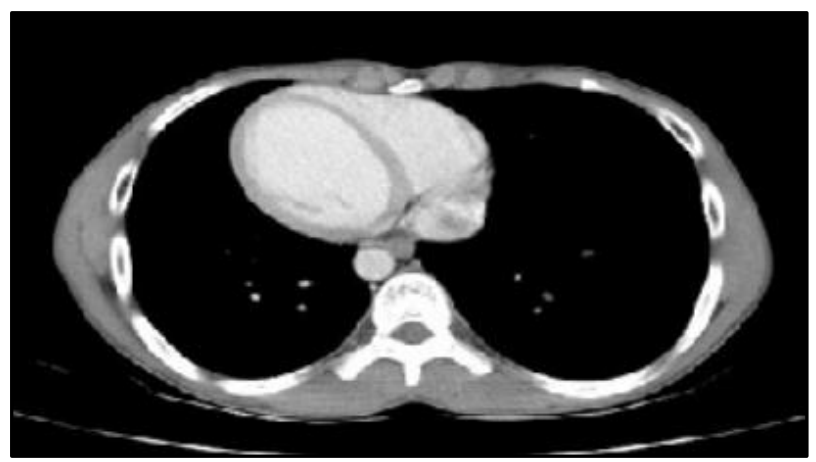

Fig. 3.1: Axial CT Thorax showing Dextrocardia

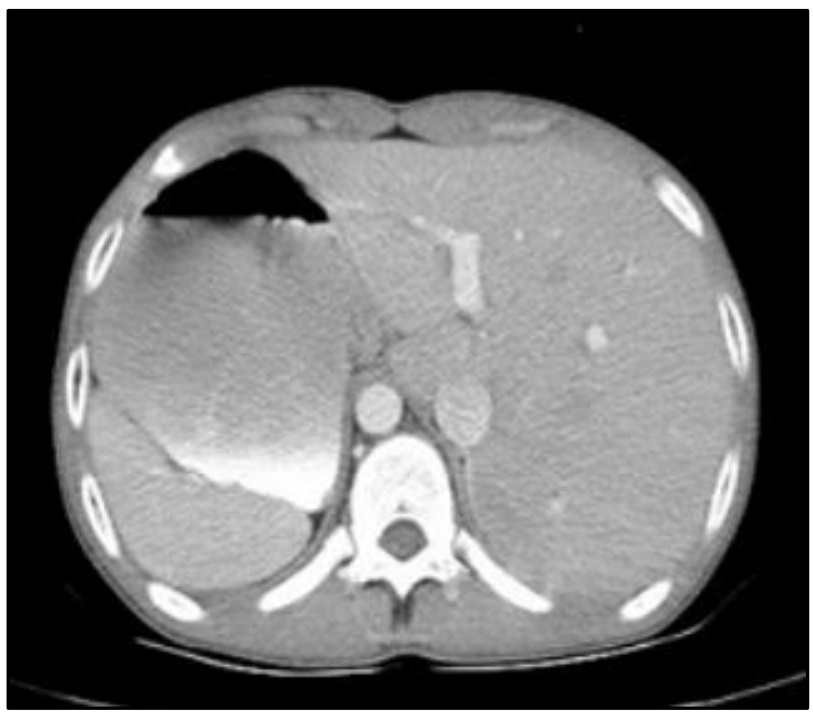

Fig. 3.2: Axial CT Abdomen showing Flip-Flop Position of Abdominal Viscera, i.e. Liver and Gall Bladder on Left Side and Stomach and Spleen on Right Side

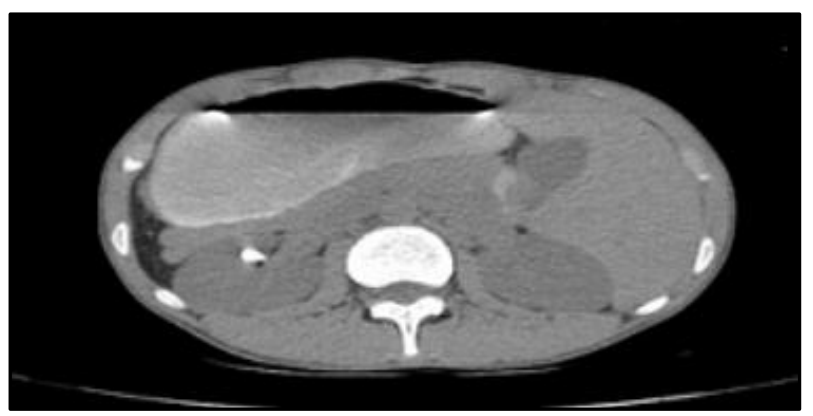

Fig. 3.3: Radiodense Calculus on Right Side with Situs Inversus

\section{CASE 2}

A 23 yr. female patient presented with left upper quadrant pain. There was no history of cough, haemoptysis or menstrual irregularity. Cardiac sounds were heard on right fifth intercostal space instead of left.

Chest X-ray showed cardiac apex in the right hemithorax with fundal gas shadow on right upper abdomen. On transabdominal ultrasound scan, left-right flip-flop of major abdominal viscera was noted with no additional finding.

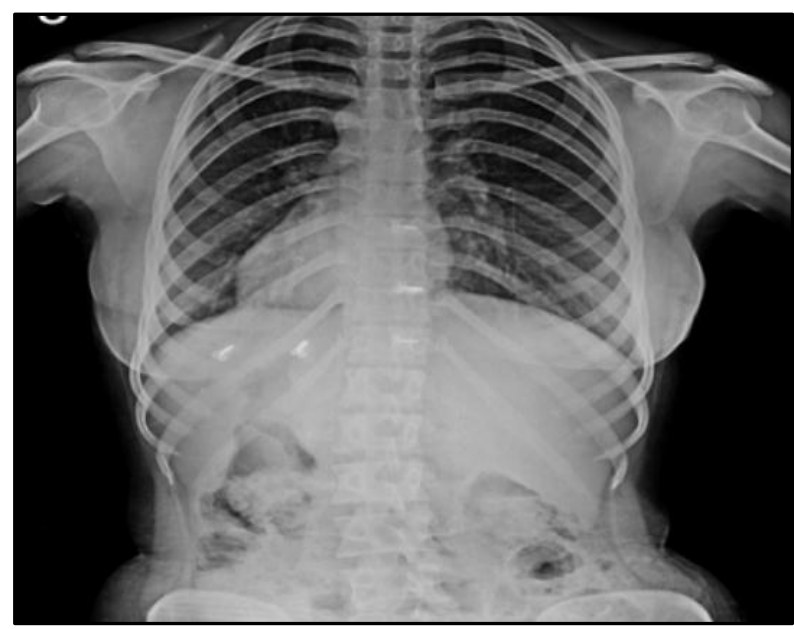

Fig. 4: X-Ray Chest (PA) View showing Cardiac Apex in the Right Hemithorax with Right-Sided Fundal Gas Shadow

\section{CASE 3}

A 14 yr. Indian male who had fever for 10 days and was referred to our department for routine ultrasound scan, which showed inverted positioning of abdominal structure with no other finding. Cardiac sounds were heard on right fifth intercostal space instead of left.

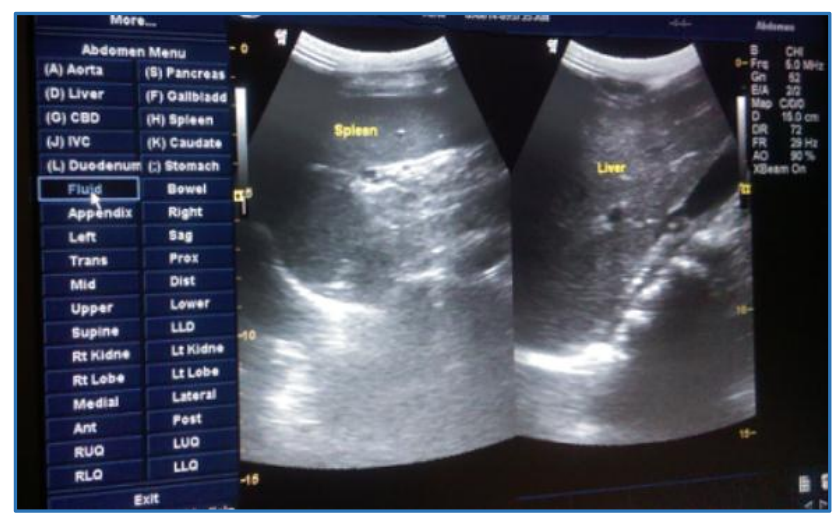

Fig. 5: Ultrasound Scan which showed Inverted Positioning of Abdominal Structure

Left-sided Electrocardiogram (ECG) revealed sinus rhythm with negative $\mathrm{P}$ wave in leads I and $\mathrm{aVL}$ along with $\mathrm{R}$ wave regression in chest leads-mirror image of normal. On rightsided ECG, P waves were still inverted in leads I, aVL with normal $\mathrm{R}$ wave progression in chest leads.

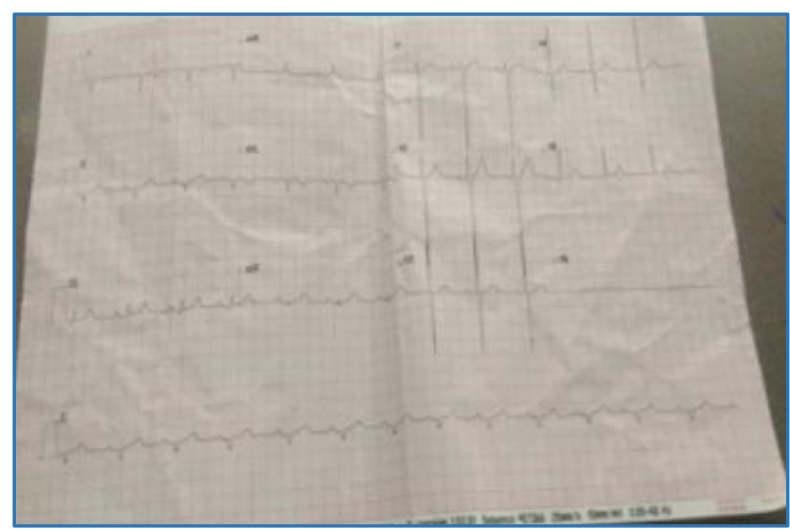

Fig. 6: ECG 


\section{CASE 4}

A 45 yr. Indian male had gross distension of abdomen for last 45 days and was sent to us for CECT abdomen. CECT scan of abdomen revealed inverted positioning of abdominal viscera and dextrocardia. There was inverted positioning of abdominal aorta and inferior vena cava in its whole length. Hiatus hernia was noted. There was evidence of chronic liver disease with features of decompensation (Ascites). There was mild bilateral pleural effusion with underlying basal lung consolidation on the right.

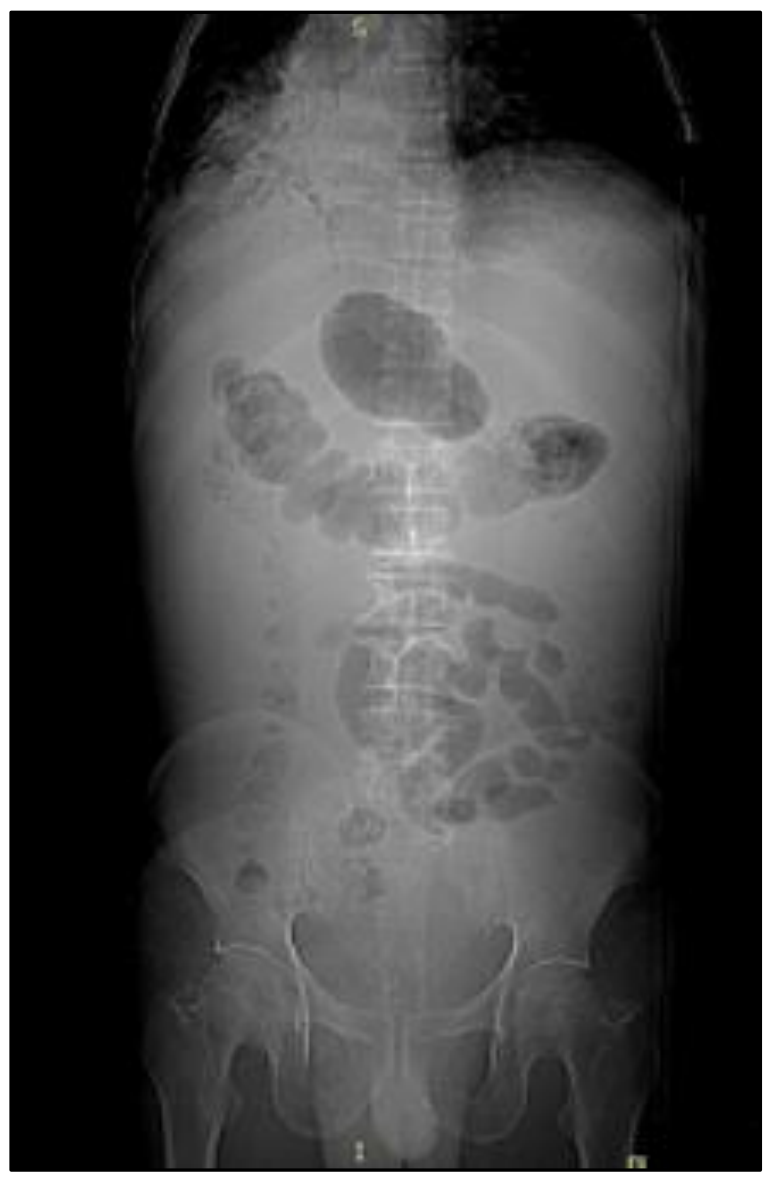

Fig. 7.1: Scout Film showing Dextrocardia

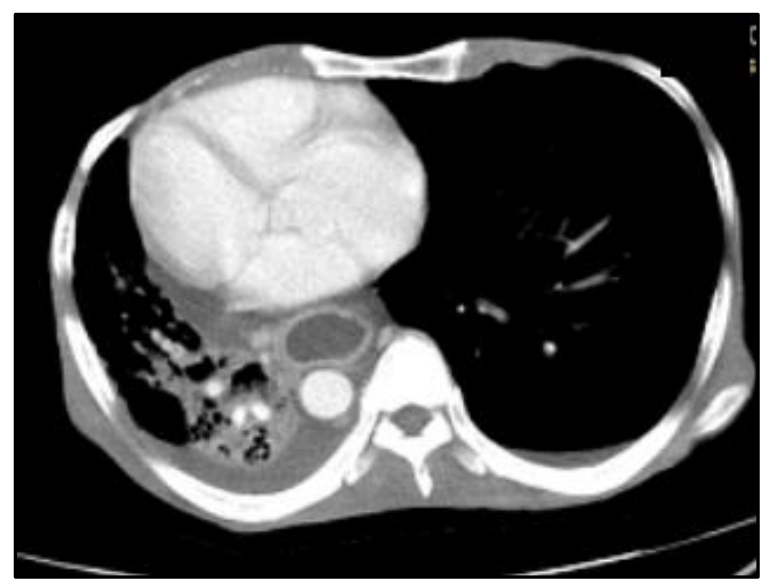

Fig. 7.2: Axial CT Thorax showing Dextrocardia with Hiatus Hernia. Mild Bilateral Pleural Effusion (Right > Left). There is Mild Underlying Basal Lung Consolidation on the Right. Descending Thoracic Aorta also seen on the Left

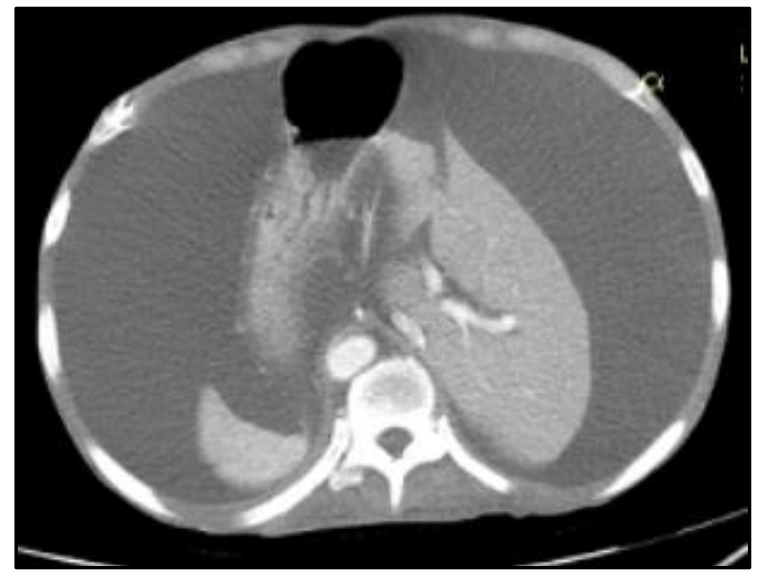

Fig. 7.3: Axial CT Abdomen showing Inverted Positioning of Abdominal Viscera and Abdominal Aorta also seen on the left. Gross Ascites also Seen

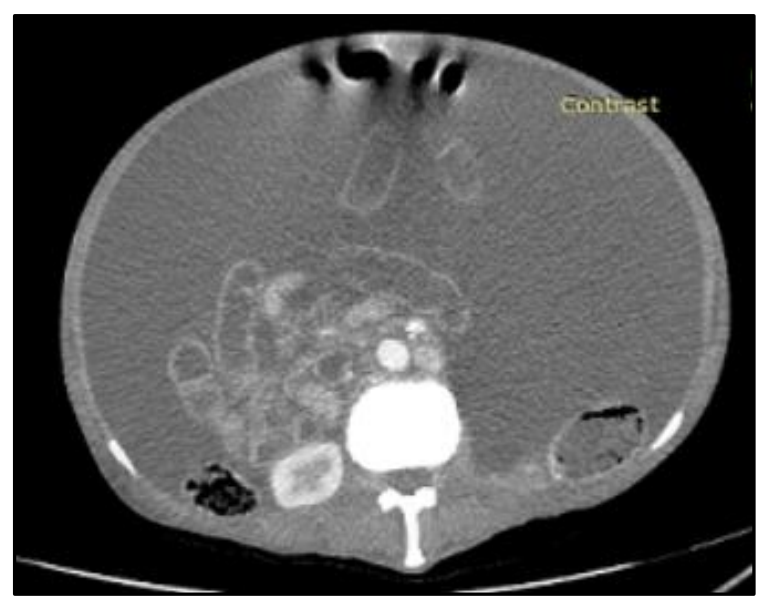

Fig. 7.4: Axial CT in Arterial Phase showing Inverted Positioning of Abdominal Aorta and Inferior Vena Cava with Gross Ascites

\section{DISCUSSION}

Dextrocardia with situs inversus is a rare condition occurring in about 1 per 10,000 population. ${ }^{1}$ There is no sex predilection. This anomaly may not be diagnosed until late in life in some cases and it is associated with primary ciliary dyskinesia and spleen malformation in some individuals. The normal pulmonary anatomy is also reversed in a manner that right lung has two lobes and left lung has three lobes.

Various genes has also been implicated for this condition. Recent studies suggest that left-right asymmetry defects are due to genetic abnormalities in lefty genes, nodal genes and ZIC 3, ACVR2B and Pitxz genes and mutation of genes present on chromosome 12.2

The arrangements of the position of the abdominal viscera in dextrocardia may be normal (Situs solitus), reversed (Situs inversus) and indeterminate (situs ambiguous or isomerism) in $32-35 \%, 35-39 \%$ and $26-28 \%$ of cases respectively. ${ }^{3}$ Situs inversus is generally an autosomal recessive genetic condition. Sometimes it can be X-linked and also found in identical twins. Dextrocardia with normal abdominal situs has a high incidence of associated congenital cardiac anomalies including transposition of great vessels and atrial and ventricular septal defects 4 in $90-95 \%$ of cases. On the other hand, dextrocardia with situs inversus is associated with lower incidence of 
congenital cardiac anomalies and relatively have normal life expectancy. It is estimated that about $25 \%$ of people with situs inversus have an underlying condition called Primary Ciliary Dyskinesia (PCD). ${ }^{5}$

The diagnosis of situs inversus is important for preventing surgical mishaps and medical misinterpretation that result from failure to recognise reversed anatomy or an atypical history. Pain from cholecystitis will be on left upper abdominal quadrant, while that of appendicitis will be on the left iliac fossa. Situs inversus also complicates organ transplantation operations as donor organs will almost certainly come from situs solitus donors.

\section{CONCLUSION}

Situs inversus with dextrocardia is rare with incidence of one in ten thousand. However, surgeons, radiologists and general practitioners should be aware of this condition as it may lead to wrong diagnosis and surgical mishaps. It also complicates organ transplantation. It further acquaints patients of his condition, so that they may avoid trauma at specific sites and also tell treating doctor in advance so that they are not mislead.
Routine premedical examination including transabdominal ultrasound scan and chest X-ray should be encouraged so that patient becomes aware of his/her condition and thereby preventing wrong diagnosis and surgical mishaps.

\section{REFERENCES}

1. Nawaz H, Matta H, Hamchou M, et al. Situs inversus abdominis in association with congenital duodenal obstruction: a report of two cases and review of the literature. Ped Surg Int 2005;21(7):589-92.

2. Supriya G, Saritha S, Madan S. Situs inversus totalis: a case report. IOSR Journal of Applied Physics (IOSR-JAP) 2013;3(6):12-6.

3. Isezuo SA, Ma'aji SM, Isah U, et al. Dextrocardia with situs viscerum total is in a 65 year old man: a case report. Niger Jour Clin Pract 2010;13(1):98-100.

4. Piryani RM, Shukla A, Prasad DN, et al. Situs inversus with dextrocardia with multiple cardiac lesions in adult. Kathmandu Univ Med Journal 2007;5(2):247-9.

5. Das DK, Shukla S. Situs Inversus - report of twins. IOSR Journal of Dental and Medical Sciences (IOSR-JDMS) 2015;14(1):69-71. Ver. IV. 